\title{
Performance Test of a Rooftop PV System in China
}

\author{
Fei-Fei JIANG ${ }^{1, a,{ }^{*}}$ and Xin-Jing ZOU ${ }^{1, b}$ \\ ${ }^{1}$ Key Laboratory of Solar Thermal Energy and Photovoltaic System, Institute of Electrical \\ Engineering, Chinese Academy of Sciences, Beijing, China, 100190

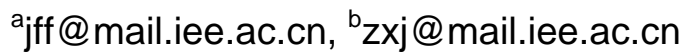

Keywords: Rooftop PV System, Power Loss, Performance Ratio.

\begin{abstract}
With the development of Photovoltaic (PV) power system, the operating quality and generating efficiency have become the major questions that people pay close attention to. PV systems are being installed in various ways and sites with different geographical and climatic condition, such as rooftop, agricultural greenhouse, lake, mountain and desert. The power system performance evaluation method should be discriminating for different system type. A rooftop PV power plant in south China was tested for performance analysis. Test items include soiling loss, power degradation, Infrared Radiation (IR) test, mismatch loss, shade evaluation, ,cable loss and inverter efficiency. The analysis results are important for improving the performance and efficiency of PV power system.
\end{abstract}

\section{Introduction}

The PV industry of China develops fast in recent years, and large-scale grid-connected PV power plants have been completed. The newly increased installed PV capacity of China in 2015 is 15GW as shown in Fig.1.. The installation type, geographical condition and climatic environment of PV power plant become various as the vast territory of China and the large installed capacity. The popular installation type is large-scale terrestrial power plant, but the proportion of distributed PV plants has been increased in recent years. The PV installation capacity of 11 provinces exceeds 100MW in 2005, and the western provinces focus on territory plants while provinces in mid-east region focus on distributed plants.

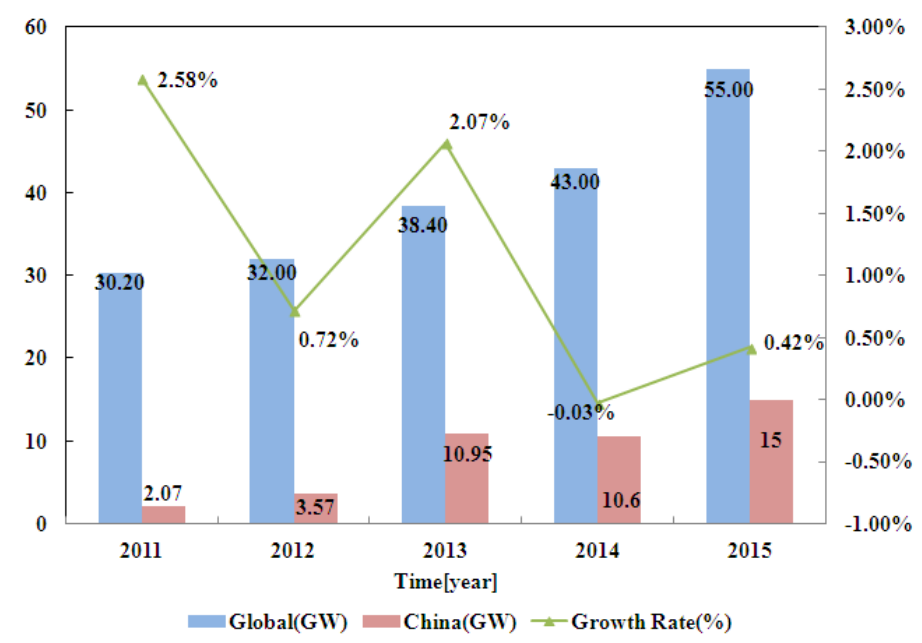

Fig 1. 2011-2015 newly increased installed capacity of global PV market

\section{Performance Test of PV System}

Performance evaluation of a rooftop PV power plant in south China was tested in September, 2015. Normative references include CNCA/CTS0016-2015 Guideline of Performance Testing and Quality Assessment for Grid-connected PV Power Plants, NB/T 32004-2013 Technical specification of grid-connected PV inverter, GB/T50797-2012 Code for construction of PV power station. Test items 
include soiling loss, degradation of PV module, mismatch loss, shade evaluation, inverter efficiency, cable loss, Infrared Radiation (IR) test of PV module.

The rooftop power plant was established in 2013 as shown in Fig.2. The installed capacity is $5247.9 \mathrm{~kW}$. The rooftop area is $110000 \mathrm{~m} 2$ or so. The rated power of PV module is $255 \mathrm{~W}$.
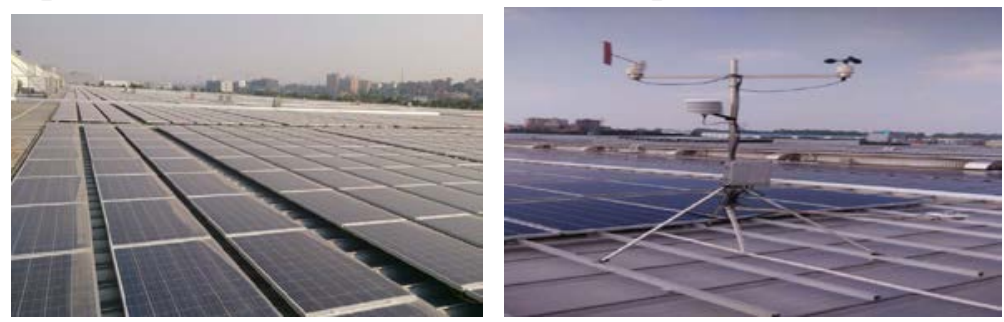

Fig 2. The rooftop PV power plant

\section{Data Analysis}

\section{Soiling Loss of PV Module}

The soiling loss of the selected string was tested before and after cleaning the modules when the irradiance exceeded $700 \mathrm{~W} / \mathrm{m}^{2}$. Record the irradiance and module I-V characteristic curve and correct these parameters to Standard Test Condition (STC). Soiling loss is calculated from formula (1).

$$
\text { Soling loss }=\frac{P_{A}-P_{B}}{P_{A}} \times 100 \%
$$

Where $\mathrm{P}_{\mathrm{A}}$ is the power that temperature and irradiance are corrected to STC after cleaning the module, $\mathrm{P}_{\mathrm{B}}$ is the power that temperature and irradiance are corrected to STC before cleaning the module.

The average soiling loss of the $20 \mathrm{PV}$ modules in the string is $1.54 \%$. The test power data and soiling loss of each module can be seen in Fig.3.

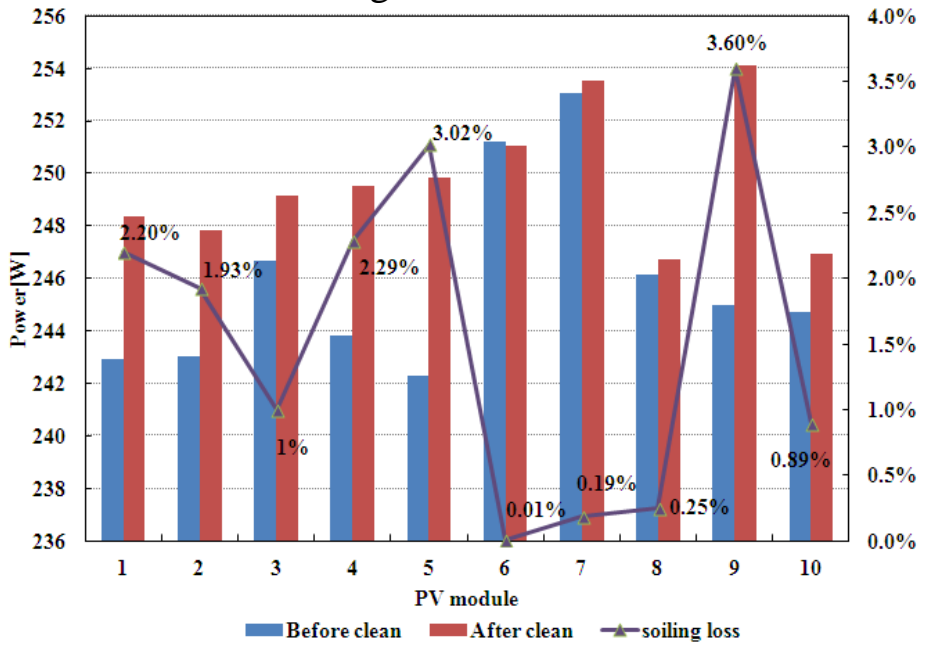

Fig 3. Test power data and soiling loss of each module

\section{Temperature Loss of PV Module}

The operation temperature of PV module is an important factor that influence the PV cell efficiency and electrical performance. When the cell operation temperature rises $1^{\circ} \mathrm{C}$ for each, the output power will reduce $0.4 \%-0.5 \%$. The temperature loss of PV module is calculated from formula (2).

$$
\text { Temperature loss }=\frac{P_{S T C 1}-P_{S T C 2}}{P_{S T C 1}} \times 100 \%
$$


Where $\mathrm{P}_{\text {STC1 }}$ is the power that temperature and irradiance are corrected to STC, $\mathrm{P}_{\text {STC2 }}$ is the power with irradiance corrected to $1000 \mathrm{~W} / \mathrm{m}^{2}$.

The average temperature loss of the $16 \mathrm{PV}$ modules is $12.5 \%$. The test power data of each module can be seen in Fig.4.

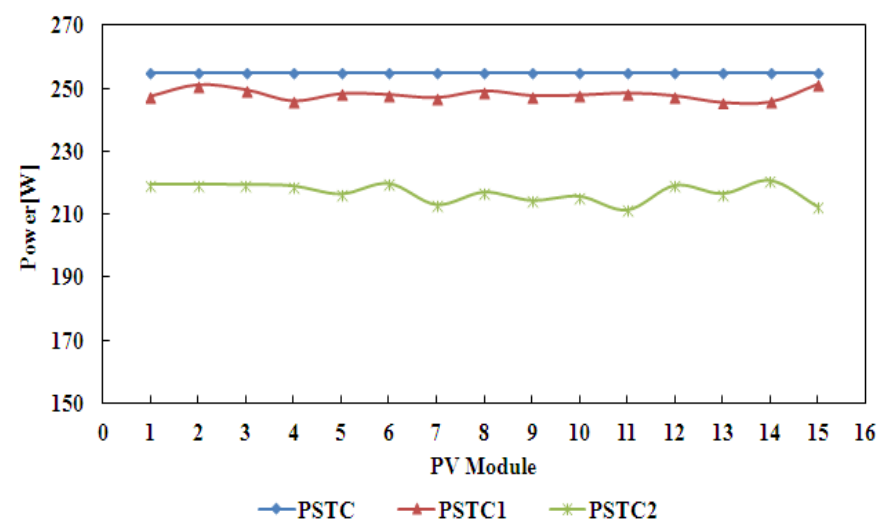

Fig 4. PV module power for temperature loss test

\section{Series Connection Loss of PV Module}

Series connection loss is caused by the performance difference between modules in a string. Modules with different encapsulation technology and electric performance installed in series will reduce the output capability of the string. The series connection loss is calculated from formula (3).

$$
\text { Series connection loss }=\frac{P_{\text {modules }}-P_{\text {string }}}{P_{\text {modules }}} \times 100 \%
$$

Where $\mathrm{P}_{\text {modules }}$ is the power sum of each module in the string, and $\mathrm{P}_{\text {string }}$ is the power of the string. All the test data are corrected to the same temperature and irradiance condition.

Four strings were selected for the series connection loss test, with 20 modules in each string. The average series connection loss of four strings is $1.78 \%$.

\section{Parallel Connection Loss of PV Module}

The distance between PV string and combiner box is different, so the voltage drop on the cable is also different. With strings from different distance connected to the combiner box in parallel, there will be parallel connection loss. One combiner box is combined with $16 \mathrm{PV}$ strings and 10 strings of a combiner box were selected for the parallel connection loss test.

$$
\text { Parallel connection loss }=\frac{P_{\text {strings }}-P_{\text {combiner }}}{P_{\text {strings }}} \times 100 \%
$$

The average parallel connection loss of 5 combiner boxes is $1.59 \%$.

\section{Cable Loss}

Cable loss includes DC loss and AC loss. DC loss includes cable from PV string to combiner box and cable from combiner to DC distribution cabinet. AC cable loss mains cable from inverter to transformer.

The average DC cable loss of 3 combiner boxes from PV string to combiner box is $0.08 \%$, the loss from combiner to DC distribution cabinet is $0.6 \%$. For the AC cable loss test, we choose 3 inverters according to the distance between the inverter and transformer, the farthest one, the middle one and the nearest one. The AC cable loss of the three cable is $0.12 \%, 0.12 \%, 0.11 \%$. The average AC cable loss is $0.11 \%$.

\section{Inverter Efficiency}

The inverter with the number of 1NB04 was selected for the efficiency test. The rated power is $500 \mathrm{KW}$. Test results of the inverter can be seen in Table 1. The max efficiency is $98.42 \%$. Fig.5 is the 
transfer efficiency curve of the inverter. The inverter weighting efficiency (China efficiency) is 98.21\%.

Table1: Test results of inverter

\begin{tabular}{|c|c|c|c|}
\hline \multicolumn{4}{|c|}{$\# 1$ NB04 inverter } \\
\hline $\begin{array}{c}\text { AC output } \\
\text { power }\end{array}$ & $\begin{array}{c}\text { DC input } \\
\text { power }\end{array}$ & Load point(\%) & $\begin{array}{c}\text { Transfer } \\
\text { efficiency(\%) }\end{array}$ \\
\hline 24.69 & 25.08 & 5 & 94.47 \\
\hline 48.32 & 49.94 & 10 & 96.76 \\
\hline 98.16 & 100.30 & 20 & 97.86 \\
\hline 147.80 & 150.25 & 30 & 98.37 \\
\hline 246.86 & 250.80 & 50 & 98.38 \\
\hline 303.06 & 307.95 & 60 & 98.41 \\
\hline 345.16 & 350.22 & 70 & 98.42 \\
\hline
\end{tabular}

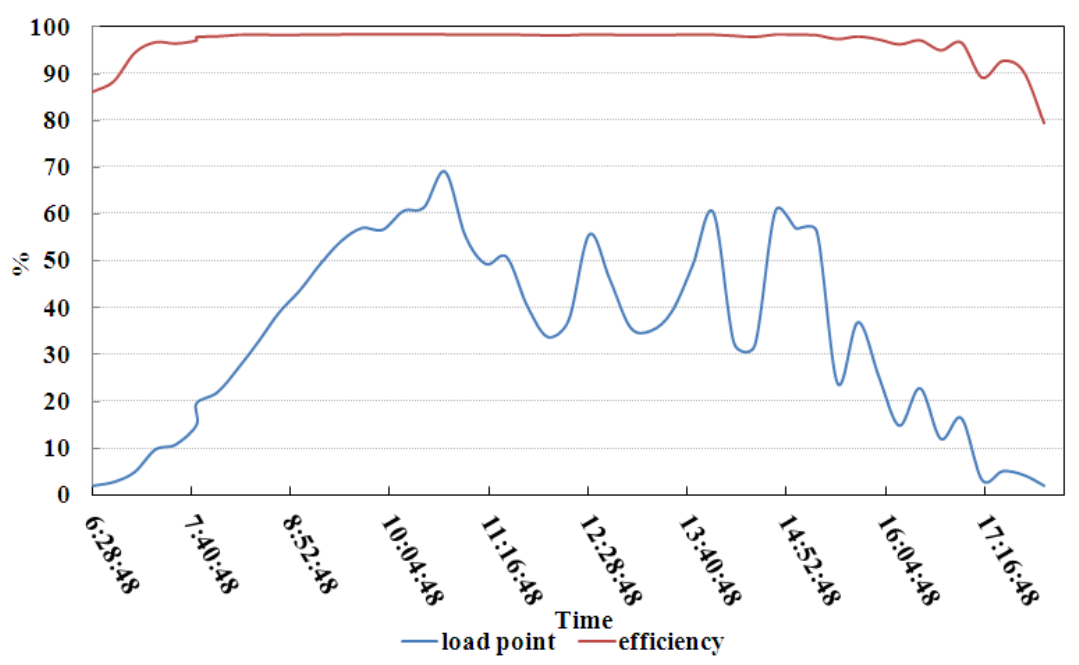

Fig 5. Transfer efficiency curve of inverter

\section{Performance Ratio of PV System}

On the basis of the power loss above, the performance ratio of the rooftop system can be figured out. Fig. 6 shows the power loss distribution of the rooftop system. The performance ratio of the system is $80.01 \%$.

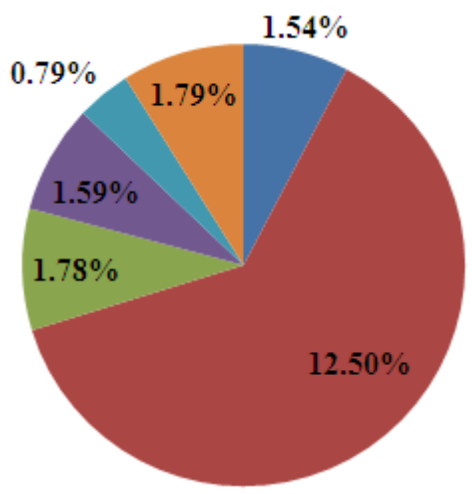

usoiling loss

temperature loss

series connection loss

- parallel connection

loss

cable loss

inverter loss

Fig 6. Power loss of the rooftop system 


\section{Summary}

The performance of a rooftop PV system was tested in this paper. The analysis results show that the performance ratio of the PV system is $80.01 \%$. There is no shading loss in the system. For different PV system type, the test and analysis method should also be different to improve the operating quality and generating efficiency.

\section{Acknowledgement}

This research was financially supported by the National Science and Technology Support Program under contract No.2015BAA09B00.

\section{References}

[1] CNCA/CTS0016: Guideline of Performance Testing and Quality Assessment for Grid-connected PV Power Plants[S].2015.

[2] IEC 61724: Photovoltaic system performance monitoring -Guidelines for measurement, data exchange and analysis[S].2014

[3] Jiang,Feifei; Liu,Haitao; Zhai,Yonghui; Zou,Xinjing.Measurement Uncertainty Analysis of Photovoltaic Cell Short-circuit Current at Standard Test Condition[C], 27th Chinese Control and Decision Conference, 5557-5561, 2015.

[4] Zou,Xinjing ; Jiang,Feifei; Liu,Haitao.Performance analysis of a rooftop PV plant and a desert PV plant[C],28th Chinese Control and Decision Conference, 6173-6176,2016. 